CUIDADOS: ASPECTOS ETICOS DEL CUIDADO

\title{
DIMENSIÓN BIOÉTICA DE LA EDUCACIÓN TERAPÉUTICA
}

\section{BIOETHICAL DIMENSION OF THERAPEUTIC EDUCATION}

Carmen Ferrete Sarriá.

E-mail: ferrete@uji.es

\section{RESUMEN}

La Educación Terapéutica (ET) es un avance en el proceso de modernización hacia una mayor autonomía de la ciudadanía en la sociedades democráticas. Pero el avance puede ser sólo aparente, si en la Educación para la Salud no se cumple con una serie de requisitos que son esenciales al proceso de enseñanza-aprendizaje. En las dos partes de las que consta el artículo se intentará: 1) Exponer la idea de que en la labor de la ET por parte del personal de enfermería no es suficiente la buena voluntad, sino que además son necesarias una serie de habilidades pedagógicas y la utilización de instrumentos didácticos. 2) Defender la idea de que una formación ética en general, además de bioética en particular, capacitará al docente terapéutico para estar a la altura de la competencia profesional que la sociedad y sus ciudadanos esperan del profesional de la enfermería.

\section{PALABRAS CLAVES:}

Ética, Corresponsabilidad, Excelencia Profesional, Educación, Autonomía 


\section{LA EDUCACIÓN TERAPÉUTICA UN AVANCE EN LA DEMOCRATIZACIÓN DE LA SANIDAD: UNA TAREA CORRESPONSABLE.}

Desde la Ilustración viene exigiéndose una mayor autonomía para toda la ciudadanía. A este proceso se llama Modernidad y consiste en que a los habitantes de las sociedades occidentales se les ha ido reconociendo el estatuto de "ciudadanos", es decir, individuos con derechos reconocidos y con potestad para decidir libremente cómo y por quién quieren ser gobernados, y qué tipo de sociedad quieren construir [1].

La salida de la "minoría de edad" heterónoma hacia una "mayoría de edad" autónoma ha sufrido diferentes avatares en los diferentes ámbitos de pensamiento y de actuación humana y no en todas las dimensiones han sido interiorizados con plenitud por la ciudadanía en los países democráticos.

En el mundo sanitario apenas hace unas décadas que comenzó el proceso de modernización. Una superación progresiva de la vigencia de un modelo paternalista en el que el médico actúa como tutor del paciente y toma las decisiones teniendo en cuenta el bien de éste. Actualmente se está imponiendo el modelo democrático, donde se concibe al paciente también como un agente de su salud.

Otro ejemplo de la incorporación del principio de autonomía en el mundo sanitario ha sido la más reciente institucionalización del Consentimiento Informado que en esencia consiste en la obligación de respetar las decisiones autónomas de los pacientes. Una autonomía fruto de la garantía del derecho de la libertad, libertad de disponer de su propio cuerpo[2].

En este congreso se aborda lo que a mi juicio es un paso más, y un paso muy importante, en ese proceso de mayor autonomía y, por tanto, hacia un mayor concepto de democracia: la Educación Terapéutica (ET). Ya que no se trata sólo de que las relaciones sanitarias estén presididas por la idea del 
consentimiento libre e informado de los ciudadanos, sino más allá de que, además de informados, participen en el proceso de cuidado de su salud.

El avance democrático puede resumirse en que los pacientes no sólo sean conscientes de sus derechos, sino además que participen como deber en su cuidado, en asumir su responsabilidad para con su salud. En definitiva, el bienestar de los ciudadano no es una cuestión exclusiva de las instituciones sanitarias, sino que debe existir una corresponsabilidad en este proceso.

El fundamento democrático que subyace a la ET es, por una parte, una mayor autonomía de la ciudadanía y, por otra parte, la idea de que en democracia educan todas las instituciones, no solamente las sanitarias. Es una tarea compartida de la educación reglada, de las instituciones jurídicas, políticas, medios de comunicación, entre otras.

Si somos autónomos, la gestión estatal (la política democrática), la justicia (incorporación de los tribunales populares), la educación (pública, obligatoria y gratuita) depende de todos, la salud también. El estado no es el responsable de todo, lo mismo pasa con la sanidad. En el reciente cambio del modelo de relación paciente-sanitario, el sanitario está haciendo los deberes, y ahora también el usuario-paciente.

Esta exigencia de participación en un modelo de "mayoría de edad ilustrada" se fundamenta en el derecho y deber del ciudadano de cuidar de su propia salud. Afrontar el reto sanitario es una cuestión de todos y para que no se den peticiones supererogatorias, las responsabilidades han de definirse claramente en tres niveles: una responsabilidad micro (el ciudadano), responsabilidad meso (de las instituciones y organizaciones democráticas) y responsabilidad macro (de las instituciones políticas y económicas que deben fortalecer el sistema de salud para la que exigencia no sea excesiva a los pacientes y las instituciones sanitarias[3]. 


\section{EDUCACIÓN PARA LA SALUd QUE DESARROLLE EL RESPETO A LA AUTONOMÍA.}

La promoción y mantenimiento de la salud no es una meta secundaria de la actividad sanitaria sino una de las finalidades básicas junto a la prevención de la enfermedad y las lesiones; aliviar el dolor y el sufrimiento causados por la enfermedad; la asistencia y curación de los enfermos y el cuidado de los que no pueden ser curados; y evitar la muerte prematura y velar por la muerte en $\operatorname{paz}[4]$.

Del mismo modo que la educación reglada, la concepción de la ET ha sido modificado desde un modelo unidireccional, a un modelo bidireccional o multidireccional donde se interpreta el paciente no sólo paciente, sino también agente de su salud. Sin embargo, todo cambio no implica progreso, podría tratarse sólo de un avance aparente y no real. Por eso, a continuación, se insistirá en la idea de que en la labor de la ET por parte del personal de enfermería no es suficiente la buena voluntad, ni la total dedicación ni una paciencia sin límites, sino que además son necesarias una serie de habilidades pedagógicas y la utilización de instrumentos didácticos, porque no toda instrucción es un auténtico proceso de enseñanza, que desarrolle el respeto a la autonomía de la persona fundamentado en el principio de dignidad humana.

Igual que no es eficiente ni eficaz cualquier método didáctico en las aulas de los centros educativos, cualquier información-educación para la salud puede contener debilidades, dificultades, riesgos y amenazas, si no se explicitan.

La actitud vital del sanitario que educa puede influir en que la ET sea realmente una tarea democrática o mera apariencia. En diferentes aspectos:

> Toda educación es educación moral[5]. Además de información terapéutica, se trasmite de un modo consciente o inconsciente nuestra 
concepción sobre cuestiones de justicia y de ideales de vida buena. Es posible que de modo inconsciente con nuestra actitud estemos trasmitiendo unas convicciones con respecto a la justicia sanitaria o un determinado modo de estar ante la enfermedad, en el mundo, que puede ser enriquecedor o contraproducente. Más vale explicitar esta dimensión moral. Es importante realizar una reflexión ética, un autoanálisis que explicite los elementos pueden intervenir en la ET.

Las creencias del educador influyen en el proceso de enseñanza. Dependiendo del nivel de desarrollo moral tendrá unos prejuicios o no con respecto a las diferencias (diferente cultura, religión, orientación sexual). Las sociedad democráticas son y deben ser, por esencia, sociedades plurales. Es importante conocer y modificar los estereotipos y los prejuicios ante determinados pacientes o grupos de pacientes. Favorecer una valoración positiva de las personas diferentes, las culturas diferentes. Sin embargo, los seres humanos no nacemos con una actitud de respeto a la diferencia. Una educación moral hacia una tolerancia activa donde no se respete todas las opiniones y actuaciones humanas, porque no todo es respetable (si rebasa los mínimos de justicia exigidos en democracia), pero sí las diferencias en máximas de felicidad[6].

- Una actitud escéptica o de confianza en el proceso educativo desmoraliza o moraliza la ET. En la tarea educativa no tiene cabida el escepticismo. La actitud debe ser de confianza de que estamos enseñando hacia una ciudadanía autónoma. Confianza en los discentes, a pesar de los errores, que forman parte del proceso educativo. Confianza y asunción de responsabilidades de la tarea educativa, pero sin demasiada carga, que inmoviliza para la acción. En los centros sanitarios como en las aulas, no todos los discentes tienen un carácter o predisposición a una mayor autonomía, pero igualmente han de ser educados: pacientes agresivos, maleducados, manipuladores, con serios problemas de higiene, etc. Manejar los sentimientos que generan determinadas personas requiere de una habilidades con las que no se nacen y que ahora se aprenden en 
los futuros docentes aprenden en las Universidades, además de con la práctica diaria para tratar todo tipo de pacientes con justicia.

También cabe señalar varios riesgos que pueden darse por parte del discente de la ET:

- Toda educación es educación moral. Ha de asumir que en la ET el propio individuo también es responsable de su curación, y no sólo el personal sanitario o la administración de medicamentos, fármacos. Posiblemente sus ideales de vida buena implique una concepción de salud asociado a belleza, juventud, perfección, bienestar y esta concepción pueda influir en la autogestión de su tratamiento. Análisis de conceptos previos, de actitudes previas problemáticas, que pueden incidir en su pronta o lenta recuperación o mantenimiento.

- Las creencias del educador influyen en el proceso de enseñanza. También en el educando intervienen sus convicciones, creencias y prejuicios con respecto al significado de enfermedad y de cuidado. La salud es una dimensión de su vida, inevitablemente conectada con su mentalidad, su estilo de vida. Además es importante realizar un autoanálisis que explicite los elementos pueden intervenir en la gestión del autocuidado.

> Una actitud escéptica o de confianza en el proceso educativo desmoraliza o moraliza la ET. Otros riesgos se centran en la falta de cultura, falta de motivación, pues no es suficiente la información hace falta la motivación que es la que le inducirá a actuar o a dejar de actuar. Tener un problema de salud o estar necesitado de tratamiento, implica una situación de vulnerabilidad extra. Una actitud de desmoralización no le permitirá tener la fortaleza y discernir con claridad. Aprender a tolerar el malestar.

Asimismo, sólo será un auténtico proceso democrático... 
$>$ Si el educando participa activamente en el proceso de ET. Si se entiende como una tarea conjunta, de colaboración, en definitiva de corresponsabilidad. El fundamento de los procesos democráticos es la autonomía, y aplicándolo al ámbito educativo, éste no puede concebirse como un proceso de instrucción (unidireccional de sanitario a paciente), sino que el paciente ha de participar en los objetivos de la ET, es decir, si ha intervenido directamente en el establecimiento de los logros, los tiempos, si se compromete en el proceso y reflexiona conjuntamente sobre el sentido de su vida, de su salud, etc.

Si en el pacto sanitario se concibe al educando como interlocutor válido, con intereses, necesidades, ideales de vida buena. No hay democracia si no existe el reconocimiento de personas con dignidad, entendido como la no instrumentalización de las personas. Que el resultado del "pacto de cuidado", no sea una negociación donde se instrumentalicen intereses particulares y no universalizables, sino un diálogo auténtico entre seres. Donde el paciente se entiende no como un ser desarraigado, sino como una red de relaciones, una red que también se urde con su enfermedad o su curación. Sin olvidar a la familia que también presta cuidados no profesionales, tanto en la enfermedad como la ET.

> Si el diálogo es un auténtico diálogo para ello hay que asegurarse que se utilizan los mismos códigos, porque el malentendido puede constituir una dificultad para el objetivo de salud. Una comunicación correcta en la dimensión verbal y no verbal. Un lenguaje con un nivel de inteligibilidad adecuado a la persona o personas que educamos. Porque de lo contrario no se cumple con objetivo de la información, requisito previo de una toma de decisiones realmente autónoma. Siempre no es fácil comunicarse con un hablante que domine nuestra propia lengua, más complicado es comunicarse con pacientes que no dominan nuestro idioma. 
$>$ Si toda la responsabilidad de la ET no reside sólo en el sanitario sino también en la organización. El problema es que nos encontramos ante organizaciones masificadas y burocratizadas que impiden protocolos personalizados y diálogos cercanos con sus usuarios. Son incompatibles las exigencias de falta de tiempo y una mayor dedición al enfermo. En esta situación, que se agrava con la actual crisis, estamos pidiendo tareas titánicas a los profesionales de la salud[7].

\section{COMPROMISO VITAL Y PROFESIONAL DE LA ENFERMERÍA.}

Como conclusión, en estas páginas se ha insistido en la necesidad de una formación ética en general, además de bioética en particular que le capacitarán en estas cuestiones para estar a la altura de la competencia profesional que la sociedad y sus ciudadanos esperan de ellos[8].

E insisto nuevamente en la propuesta de capacitar al futuro profesional de la medicina a formarse en cuestiones éticas que le permitirán empatizar con sus enfermos, apreciar sus valores e intereses, conocer sus expectativas vitales, fomentar virtudes éticas como la compasión, la tolerancia, la solidaridad o la responsabilidad, y dirimir con prudencia en el caso de conflicto moral[9].

En el perfil de ingreso al grado de enfermería de la Universitat Jaume I, se destaca esta necesidad del siguiente modo: "una persona con un importante compromiso ético y social, con gran capacidad de servicio a la comunidad en estados de salud, de enfermedad y acompañamiento en la muerte digna. Ha de ser una persona capaz de actuar con rapidez profesional en emergencias sanitarias, atender a la población sana a través de consejos de educación para la salud o suplir la autonomía humana." 
En definitiva, la ET también contiene un compromiso ético, porque incide una obligación moral ya que la sociedad tiene altas expectativas con respecto a los sanitarios porque en sus manos ponen uno de los valores más importantes para todas las personas: su vida, su salud.

En resumen:

$\checkmark$ La necesidad de la corresponsabilidad de la Educación Terapéutica Democrática

$\checkmark$ La profesión del sanitario-docente entendida como un compromiso vital, a la vez personal y social.

[1] Cfr. ADELA CORTINA: Ética aplicada y democracia radical, Tecnos, Madrid, 1993.

[2] Cfr. CARMEN FERRETE: "Potencialidades y limitaciones bioéticas de los consentimientos informados", en Diálogo filosófico, n. 41, 2012 (en prensa).

[3] DOMINGO GARCÍA-MARZÁ: Ética empresarial. Del diálogo a la confianza, Trotta, Madrid, 2004.

[4] ADELA CORTINA: "Ética, tecnología y salud" en Ma del Mar García (ed.) Ética y Salud, EASP, Granada, pp. 25-38, 1998

[5] ADELA CORTINA: Ética de la razón cordial. Educar en la ciudadanía en el siglo XXI, Ediciones Nobel, Oviedo, 2007.

[6] CARMEN FERRETE: Ética aplicada como ética ecológica. Educación cívica y responsabilidad ecológica, Ediciones de las Ciencias Sociales, Madrid, 2010.

[7] DOMINGO GARCÍA MARZÁ (dir.): La apuesta ética en las organizaciones sanitarias, Universitat Jaume I, Colecció Humanitats, Castellón, 2005.

[8] JULIO VIELVA: Ética de las profesiones. Enfermería, Desclée de Brouwer, Bilbao, 2002.

[9] VICTORIA CAMPS: "La excelencia en las profesiones sanitarias", en Humanitas, Humanidades médicas, n. 21, 2007, pp. 1-13. 